\title{
Indefinite Determiners and the Pragmatics of Referential Anchoring*
}

\author{
Edgar Onea and Ljudmila Geist \\ University of Göttingen and University of Stuttgart, Germany \\ edgar.onea@zentr.uni-goettingen.de and Ljudmila.Geist@ling.uni-stuttgart.de
}

\begin{abstract}
In this paper we propose a unified framework for the representation of different types of indefinite pronouns and determiners in terms of referential anchoring. Referential anchoring is a pragmatic operation that establishes a functional dependency between the referent of an indefinite DP and some other discourse item. As such, the idea of referential anchoring is not new (cf. Kratzer, 1998; von Heusinger, 2002; Kamp and Bende-Farkas, 2010, etc.), however there is some confusion in the discussion of referential anchoring regarding exceptional scope readings. We claim that referential anchoring is independent of scope, even though referentially anchored functional readings often entail exceptional scope readings. We make a transparent formal proposal for referential anchoring that draws on the idea of domain narrowing in the sense of Schwarzschild (2002). Finally, we present the advantage of our analysis by applying it to the Russian indefinite determiners kakoj-to, koe-kakoj and kakoj-nibud'.
\end{abstract}

\section{Keywords}

indefinites, domain reduction, Skolem functions, referential anchoring

\section{Introduction}

It has been observed by Haspelmath (1997) and many others that, crosslinguistically, there is a great amount of variation in the meaning of indefinite

* Work on this paper has been supported by the project C2 "Case and referential context" of the SFB 732 "Incremental Specification in Context" at the University of Stuttgart funded by the German Research Foundation (DFG), and by the Courant Research Centre "Text Structures" at the University of Göttingen funded by the German Initiative for Excellence which we acknowledge with gratitude. We would like to thank Cornelia Ebert, Udo Klein, and the audience of the JSM conference in Paris 2009, especially Donka Farkas, for comments on previous versions of this paper. In addition we would like to thank Klaus von Heusinger and Hans Kamp for many fruitful discussions. Without their input this paper would not have been possible. We thank Anna Volodina and Alexej Chibakov for the discussion on Russian data. Finally we are indebted 
pronouns and determiners. The notion of specificity has often been called upon to account for some of the arising contrasts (cf. von Heusinger (2011) for a recent multi-layered proposal), but for the time being a unified semantic framework for dealing with this variation is still lacking, partly because it is often unclear what exactly such a framework should be able to model: in particular, whether for instance epistemic specificity, i.e. identifiability by the speaker, and exceptional scope readings over scope islands are the same phenomenon or not. We attempt to deliver such a framework in this paper that partly contributes to disentangling these phenomena.

In particular, we develop a unified analysis for three Russian indefinite determiners that might seem unrelated: the epistemically specific koe-kakoj, the scopally-specific kakoj-to and the non-specific kakoj-nibud' (terms from Farkas, 1995). Our analysis improves in predictiveness on previous approaches like Kagan (2007), Yanovich (2005) and Pereltsvaig (2008). In addition, it has the advantage that it uses exactly the same representational format for all three determiners such that the difference between their meanings boils down to different constraints on a more general pragmatic mechanism that we call referential anchoring (term from von Heusinger, 2002).

The basic idea of referential anchoring is very simple and widespread across the literature: an indefinite establishes a functional dependency between some discourse item and the "intended referent". There have been a number of implementations of this idea: most influentially, Kratzer (1998) uses Skolemized choice functions (see also von Heusinger, 2002), but one can alternatively use plain Skolem functions as shown in Bende-Farkas and Kamp (2001), cf. also Steedman (2007), Endriss (2009) and from another pragmatic perspective Dekker (2008).

We propose a particular formalization of referential anchoring, which is mathematically nearly equivalent with Kratzer (1998) but comes with some conceptual advantages. We take this to be very important, so we will briefly outline it in the following.

In particular, we suggest (similar to Dekker, 2004, 2008) that referential anchoring is - at its very core - a pragmatic phenomenon. Using an indefinite the speaker generally introduces a new discourse item, which for reasons of simplicity we model in a classical way as an existential quantifier. However, the speaker may have so-called referential intentions whenever using an indefinite. These intentions could be translated into saying that he has a particular individual in mind or some dependency on other individuals, which, for Dekker

to the editors of the International Review of Pragmatics, especially Ken Turner, for valuable comments. Of course, all remaining shortcomings are our own. 
$(2004,2008)$, is a specific pragmatic dimension of the interpretation of indefinites. However, one could also think of these referential intentions in terms of domain narrowing, as in Schwarzschild (2002): if the speaker utters (1), she may on the one hand commit herself to the truth of (1a) but, in addition, she may also mean that not any boy will do, but only a subset of the boys $\mathrm{C}$, which may ultimately contain only the one and only boy he actually sees swimming. We side with Schwarzschild (2002) here because we do not see the conceptual gain of additional levels of meaning representation.

(1) A boy swims.

a. $(\exists x)(\mathrm{B}(x) \& \mathrm{~S}(x))$

b. $(\exists x)(\mathrm{B}(x) \& \mathrm{C}(x) \& \mathrm{~S}(x))$

If referential anchoring is indeed a domain narrowing mechanism, it should be represented as such. For this reason we assume that referential anchoring amounts to including a functional dependency into the restrictor of an existential quantifier. The advantage is that this makes the relation between a plain indefinite and a referentially anchored one transparent, in contrast to Kratzer's (1998) ambiguity approach. Of course, as soon as referential anchoring gets lexically coded, as in the case of the indefinite determiners we analyze in this paper, the pragmatic dimension goes away and we end up saying something very similar to Kratzer (1998), but we do not need choice functions, which we take to be a real conceptual advantage. We discuss this point at some length.

Our proposal also differs from Dekker (2008). Our domain narrowing is just as pragmatic as Dekker's system, but it doesn't include any special dimension of meaning. This apparently comes at a cost: our approach fails to model the scope-island violating behaviour of indefinites in a straightforward way (just like Kratzer, 1998, and as far as we can reconstruct also Dekker, 2008, himself). We discuss this issue in Section 1 and argue that this is a desirable consequence, for we think exceptional, island-violating, scope for indefinites should not be modelled with referential anchoring in the first place. The reason is simply that a) referential anchoring, as we understand it, is a means to deal with functional readings, and b) as Schwarz (2001) argues, functional readings are different from genuine scopal readings. We will extend the results of Schwarz (2001) and say that there is no obvious reason to assume that functional readings involve an island-constraint violation. And there is also no obvious reason why there should be any kind of referential anchoring at work in genuine exceptional scope readings.

We do not propose here a theory of exceptional wide scope for indefinites. For explicitness, we will follow Endriss (2009) in assuming that indefinites are free to move out of scope islands whenever they are topical. Alternatively one 
can use an independence friendly logical approach to the existential quantifier which allows scope out of islands, as in Farkas and Brasoveanu (2009) but as far as we can see, there is way too little clarity in the data patterns to make anything hinge on this particular decision (cf. Ionin, 2010, for new experimental data suggesting that not only bona fide indefinites can escape scope islands and Heim, 2011, for a similarly sceptical review of the situation). So, our proposal is meant to be independent of whatever theory may prove best for the scope of indefinites, as long as indefinites are treated as quantificational, in the sense that they have something like a restrictor.

Summing up, in this paper we provide a particular notation of referential anchoring based on a domain narrowing operation, we show with examples from Russian that referential anchoring can account for some surprising variation in the meaning of indefinite determiners - which is the main empirical contribution of our paper - and we claim that a large part of what referential anchoring cannot do, namely modelling genuine scopal readings, is actually an independent issue.

The structure of this paper is as follows: first, we discuss the difference between functional readings and genuine scopal readings. Then, we lay out a formalism for referential anchoring as domain narrowing. Finally, we present the analysis of the Russian indefinite pronouns and open some further research questions.

\section{Functional Readings and Domain Narrowing}

The aim of this section is to show that functional readings and exceptional scope readings are unrelated and need not be modelled by one and the same mechanism. We propose that functional readings are always instances of domain narrowing and thereby neutralize scope. In other words, Schwarzschild (2002) was right about functional indefinites (although wrong about plain exceptional scope readings). We propose a particular formal representation of functional readings as domain narrowing and argue that it has some advantages compared to Kratzer (1998).

\subsection{Functional Readings vs. Scopal Readings}

In this section we argue that functional readings exist and must be represented in the semantics of particular indefinite determiners.

Compare (2a) and (2b) (adapted from Hintikka, 1986). In the most prominent reading of (2a) some date has narrow scope under each husband, hence the sentence says that for each husband there is a date that he forgot. 
(2b) apparently expands on this by specifying which date each husband forgot. The pronoun his is bound by every husband and the whole apposition specifies a function which assigns particular dates to married men, i.e. the date of their wife's birthday. Readings like (2b) are known as functional readings.(2)

(2) a. Each husband had forgotten some date.

b. Each husband had forgotten some date - his wife's birthday.

(2) does not establish that functional readings are genuine readings of indefinites, however. In (2) the functional narrow reading can be seen as a special case of the plain narrow scope reading. On the narrow scope reading (2a) entails that there is a function which assigns to every husband a date he had forgotten ((3a) and the Skolem Form ( $3 b$ ) are equivalent) and in (2b) this function is specified as his wife's birthday, as shown in (3c). For deriving this, one does not need to assume that (2) actually has a semantically derivable functional reading.

(3) a. $(\forall x)(\mathrm{H}(x) \rightarrow(\exists y)(\mathrm{D}(y) \& \mathrm{~F}(y)(x)))$

b. $(\exists f)((\forall x)(\mathrm{H}(x) \rightarrow \mathrm{D}(f(x)) \&(\forall x)(\mathrm{H}(x) \rightarrow \mathrm{F}(f(x))(x)))$

c. $(\exists f)((\forall x)(\mathrm{H}(x) \rightarrow \mathrm{D}(f(x)) \&(\forall x)(\mathrm{H}(x) \rightarrow \mathrm{F}(f(x))(x) \& f=\lambda z . l y . \mathrm{WB}(z)(y)))$

One can show, however, that functional readings are genuine readings that must be semantically coded in some way. (4), the original example from Hintikka (1986) allows for the continuation in (4a) but a continuation like ( $4 \mathrm{~b})$ is no good. The essential difference between (4a) and ( $4 b)$ is that the former represents a sensible/natural function (Chierchia 1993), ${ }^{1}$ while (4b) contains a random set of ordered pairs and there is no ground for assuming that there is any natural function which has such random values. Hence the generalization seems to be that a certain requires that dates are assigned to husbands in a natural, systematic way. A non-systematic pair list will not suffice to identify this function.

(4) Each husband had forgotten a certain date

a. ... his wife's birthday.

b. ... \#John had forgotten Mary's birthday, Michael his wedding anniversary etc.

1 There are also other notions in the literature that capture the same intuition. Ebert and Endriss (2007) argue that such functions must be nameable in natural language, Sharvit (1997) speaks of salient functions. To better capture the intuitions behind what is often called natural function Jacobson (1999: 160) suggests the notion of procedurally defined functions. She points out that a random list of ordered pairs - while extensionally equivalent to a procedurally defined function - does not count as a "function" in this sense. We will stick with Jacobson's notion of procedurally defined functions in this paper, but call it natural for simplicity. 
It follows that (3a) or the equivalent ( $3 \mathrm{~b})$ is not an appropriate representation of (4), since it doesn't rule out the continuation in (4b). A better candidate would be (5a), which restricts the number of functions under consideration to the natural ones. (5a), on its own, is stronger and hence asymmetrically entails (3a) and (3b). Note that we use the Skolem form in (5a) for reasons of simplicity and not of necessity, one could include the functional dependency in a plain representation as an existential quantifier as well, as somewhat redundantly done in $(5 b)$.

(5) a. $(\exists f)((\forall x)(\mathrm{H}(x) \rightarrow \mathrm{D}(f(x))) \&$ natural $(f) \&(\forall x)(\mathrm{H}(x) \rightarrow \mathrm{F}(f(x))(x)))$

b. $(\exists f)((\forall x)(\mathrm{H}(x) \rightarrow \mathrm{D}(f(x))) \& \operatorname{natural}(f) \&(\forall x)(\mathrm{H}(x) \rightarrow(\exists y)(\mathrm{D}(y) \& f(x)=y$ $\& F(y)(x)))$

The negation of (4) given in (6a) allows for the functional reading in (6b). Crucially, (6b) is entailed by the negation of the narrow scope reading of (2a), given in (6c). Even more importantly, (6a) does not have the negation given in $(6 c)$. (At the same time, it is unclear whether $(2 a)$ does have the reading in (6b), but even if this reading exists, it cannot be derived from the plain existential quantifier reading without further additions, as there is no configuration under which the negation scopes over the universal quantifier and under the existential quantifier and the existential quantifier still scopes below the universal.)

(6) a. Not every husband had forgotten a certain date.

b. $(\exists f)((\forall x)(\mathrm{H}(x) \rightarrow \mathrm{D}(f(x)) \&$ natural $(f)) \& \neg(\forall x)(\mathrm{H}(x) \rightarrow \mathrm{F}(f(x))(x))$

c. $\neg(\forall x)(\mathrm{H}(x) \rightarrow(\exists y)(\mathrm{D}(y) \& \mathrm{~F}(y)(x)))$

If this is correct, a functional narrow reading is not purely pragmatic and needs to be coded as part of the meaning of expressions like a certain date. This leaves open the question whether an indefinite like some date is ambiguous between a functional and a non-functional reading, and also the question what is the right way to model functional readings. What it does show, however, is that at least in downward entailing contexts functional readings can occur without corresponding plain scopal readings.

Before going further, a note on terminology is in order. We will not use the term scope in naming functional readings: we shall call them narrow functional readings, whenever the referent of the indefinite depends on the quantifier with the narrowest possible scope (disregarding the indefinite), intermediate functional readings whenever it depends on a quantifier with some wider scope, and wide functional readings whenever it depends on some extra-sentential 
item. ${ }^{2}$ Note that it is not easy to distinguish between wide functional readings and plain wide scope readings.

After having established that functional readings exist and that they should be modelled as part of the meaning of indefinite determiners like a certain (and possibly also of some), we now turn to the question how functional readings should be modelled.

\subsection{Exceptional Scope and Functional Readings}

Schwarz (2001) claims that functional indefinites should/could be analyzed in terms of Skolemized choice functions in the sense of Kratzer (1998). We propose that functional indefinites need not be analyzed that way, because there is a simpler way to do it. However, we agree with Schwarz (2001) contra Kratzer (1998) that plain exceptional scope readings should be analyzed differently from functional readings. We do not discuss alternative analyses, but refer to Bende-Farkas and Kamp (2001), Schwarz (2001) and Endriss (2009) for exhaustive overviews of the choice functional analyses proposed in the literature.

Kratzer (1998) assumes that indefinites are ambiguous between plain existential quantifiers as (7a) and so-called Skolemized choice functions. Simplifying somewhat, Skolemized choice functions are functions of type $\langle e,\langle\langle e, t\rangle, e\rangle\rangle$. They take a variable as an argument and return a choice function, which takes a set and returns one of its members $(\langle\langle e, t\rangle, e\rangle)$. So, an indefinite like $a$ boy is ambiguous between the representation as an existential quantifier, given in (7a), and the choice function representation in (7b). A functional indefinite like a certain boy will only have the choice function representation in (7b), however. Kratzer's notation is a bit different but amounts to the same in all respects. In Kratzer's system $f$ is contextually determined, however, $y$ can be bound sentence-internally as well. This allows her to model the example (4) as shown in (8), where $f$ is treated as some salient natural contextual function.

(7) a. $[[$ a boy $]]=\lambda \mathrm{Q} \cdot \lambda x \cdot \exists \mathrm{x} \cdot \operatorname{boy}(x) \& \mathrm{Q}(\mathrm{x})$

b. $[[$ a (certain) boy $]=f(y)(\lambda x$. boy $(x))$

(8) $(\forall x)(\mathrm{H}(x) \rightarrow \mathrm{F}(\mathrm{f}(x)(\mathrm{D}))(x))$

2 Endriss (2009) uses a different terminology. She calls functional intermediate readings functional wide scope readings on the intuition that in this reading the function variable has widest scope. However her terminology would not allow the distinction between functional intermediate and functional narrow readings. 
Historically, Kratzer's (1998) system has a number of advantages over the analyses she intends to expand, but from today's point of view, as we see it, the use of choice functions seems unnecessary. To explain this point we start with some very brief background.

Probably the most famous commonplace about indefinites is that they can scope out of scope islands (Fodor and Sag, 1982), whereas other quantifiers cannot. For example the universal quantifier every football player in (9) can take local scope inside the relative clause, as paraphrased in (9a), but not wide scope, as in (9b), while in (10) the indefinite some football player has both the local scope reading given in (10a) and the reading in (10b). Readings like (10b) are known as exceptional (wide) scope readings. In analyzing (10b) one should, if possible, preserve the syntactic island constraints and avoid a representation with the structure given in (10c), for in that case the existential quantifier is in a syntactically illicit LF-position.

(9) John read every book that every football player signed.

a. Existing reading: John read every book that was signed by all football players.

b. Non-existing reading: For every football player, John read every book he signed.

(10) Every girl read every book that some football player signed.

a. Existing reading: Every girl read every book that was signed by any football player.

b. Existing reading: There is a football player such that every girl read every book signed by him.

c. $\exists \mathrm{FP}(\forall \mathrm{G}(\forall \mathrm{B}(\mathrm{R})))$

Fodor and Sag (1982) proposed to analyze indefinites such as some football player as in (10b) as an individual constant. This means that the indefinite is no longer a quantifier but a constant having the value of the individual football player the speaker has in mind when uttering (10). However, it turns out that intermediate scope readings are also possible, as paraphrased in (11). This is not predicted by the analysis of indefinites as constants, and again, an LF of the type (11a) is syntactically illicit.

(11) For every girl, there is a football player, such that she read every book that he signed. a. $\forall \mathrm{G}(\exists \mathrm{FP}(\forall \mathrm{B}(\mathrm{R})))$

Here is a very simple-minded solution: take the Skolem-form of the plain intermediate scope representation. Now it is the function variable that leaves the scope island. This is not very satisfying, though, since the actual semantic contribution of the indefinite, both its lexical restrictor and its existential force are still outside the scope island - in other words, this is just a notational difference compared to a plain existential quantifier. 


$$
(\exists f)((\forall x)(\mathrm{G}(x) \rightarrow \mathrm{FP}(x)) \&(\forall x)(\mathrm{G}(x) \rightarrow(\forall y)(\mathrm{B}(y) \& \mathrm{~S}(f(x))(y)) \rightarrow \mathrm{R}(x, y)))
$$

It is possible, however, to leave the descriptive material in situ, by introducing choice functions. A choice function will take the descriptive material of the indefinite and return one of its members, i.e. it is a function of type $\langle\langle e, t\rangle, e\rangle$. Here, we use the Reinhart (1997)/ Winter (1997) style notation.

$$
(\forall x)(\mathrm{G}(x) \rightarrow(\exists f)(\mathrm{CF}(f) \&(\forall y)(\mathrm{B}(y) \& \mathrm{~S}(f(\mathrm{FP}))(y)) \rightarrow \mathrm{R}(x, y)))
$$

Obviously (12) and (13) are equivalent, except for the way they handle the case in which there are no football players at all. In this case the Skolem function variant will predict falsity and the choice function variant will predict oddity (i.e. undefinedness), but Schwarz (2001) shows that this part is not essentially dependent on choice functions as such.

There are a number of reasons why a choice function analysis along these lines is not very helpful. For one thing, it cannot model intermediate functional readings at all, furthermore it runs into an overgeneration problem discussed in Schwarz (2001) that is irrelevant for our argumentation, and most obviously, the conceptual gain in introducing a choice function with regard to the use of a Skolem function is anything but obvious: after all, the existential quantifier is still outside the scope island, and if this was a problem for Skolem functions, why would it be less problematic for choice functions? This is even more dramatic, as the existential closure of Skolem functions is a default widest scope operation, whereas choice functions have to be existentially closed in the scope of other quantifiers in the sentence. In a way, then, choice functions simply emulate scope, transferring the essential step of existential closure onto the function variable in the way Skolem functions do, but their interpretation crucially depends on the position of the existential closure in the logical form. In addition, Schwarz (2001) also shows that the resulting LF representations with choice functions tend to get dubious.

Note that unlike Skolem functions, choice functions do not have the potential to model intermediate functional readings. The reason is very simple: there is nothing in a plain choice functional representation that would actually model the functional dependency arising in functional readings.

Kratzer (1998) solves this problem by adding a so-called Skolem variable to the representation and eliminating existential closure altogether. The Skolem variable takes care of the functional dependency as already shown above. The same formalism also models widest scope, since the Skolem variable may be bound sentence-externally, or simply be a constant like the speaker. This is a clear advantage of Kratzer (1998) over Reinhart (1997)/ Winter (1997) and some other related analyses. However, Chierchia (2001) 
and even more explicitly Schwarz (2001) show that Kratzer (1998) cannot model plain intermediate scope readings for indefinites.

Consider for example (14a), which illustrates the famous Chierchia (2001) problem: the example has the reading paraphrased in (14b). This reading can be derived with the system proposed by Kratzer and is given in (14c). Note that as long as the variable $f$ is not existentially bound, (14c) is not a fully correct representation of (14b), but if one binds the $f$ variable at the highest possible level of sentential representation, as in Matthewson (1999), the difference disappears, as shown in (14d).

(14) a. Every woman ate all the cookies some man has brought.

b. For every woman there is a man such that she ate all cookies he brought.

c. $(\forall x)(\mathrm{W}(x) \rightarrow(\forall y)(\mathrm{C}(y) \& \mathrm{~B}(f(x)(\mathrm{M}), y) \rightarrow \mathrm{A}(x, y)))$

d. $(\exists f)((\forall x)(\mathrm{W}(x) \rightarrow(\forall y)(\mathrm{C}(y) \& \mathrm{~B}(f(x)(\mathrm{M}), y) \rightarrow \mathrm{A}(x, y))))$

This reading can also be negated as in (15a) giving rise to a reading that is formally given in (15c) and can be paraphrased as in (15b).

(15) a. Not every woman ate all the cookies some man has brought.

b. It is not the case that for every woman there is a man such that she ate all cookies he brought.

c. $\neg(\forall x)(\mathrm{W}(x) \rightarrow(\exists z)(\mathrm{M}(z) \&(\forall y)(\mathrm{C}(y) \& \mathrm{~B}(z, y) \rightarrow \mathrm{A}(x, y))))$

This reading is verified by a woman for whom there is no man such that she ate all the cookies he brought. It is easy to see that such a reading cannot be represented in Kratzer's (1998) system, because if the choice function is not existentially bound inside the negation, we will always get readings that negate the cookie eating for pairs of men and women but no reading that actually claims that there are no such pairings. On the other hand, if the choice function were existentially bound inside the scope of negation, other problems would arise in other types of examples we do not wish to dwell upon here, since we independently know that Kratzer (1998) does not allow for existential binding of the choice functions inside the clause in the first place, cf. Bende-Farkas and Kamp (2001) and Schwarz (2001) for a very detailed discussion of this point.

As noted above (14c) is itself not a plain intermediate scope reading. Kratzer (1998) actually predicts a functional reading in which there is a specific contextually identifiable function which assigns cookie-bringing-men to women, e.g. their fathers-in-law, and then it is asserted that every woman ate every cookie brought by the man assigned to her by that function. We have seen already that functional readings entail the corresponding plain scopal reading but negating the sentence as in (15) shows that the readings are different. So, Kratzer (1998) cannot derive the plain intermediate scope under negation 
not because her system has a problem interacting with negation but because it was never designed to derive plain scopal readings (even though apparently intended otherwise by Kratzer) and it only apparently derived such readings in upward entailing contexts. Still, while Kratzer (1998) cannot derive real scopal readings, she provides an excellent account for functional readings.

Indeed, Kratzer (2003) correctly argues that, while Chierchia's (2001) criticism is right, (15) does have a functional intermediate reading that is predicted by her approach, a reading such that assuming some salient pairing of women and men, the negation only refers to such pairs as shown in (16) and formally represented in (16a).

(16) Not every woman ate all the cookies some man has brought, namely her father-in-law.

a. $\neg(\forall x)(\mathrm{W}(x) \rightarrow(\forall y)(\mathrm{C}(y) \& \mathrm{~B}((f(x)(\mathrm{M})), y)) \rightarrow \mathrm{A}(x, y)))$

Given this situation, Schwarz (2001) concludes that we may need both Kratzer's (1998) choice functional approach and some scope shifting theory: one for functional readings, and one for true scopal readings.

There is nothing new in our argumentation so far, but now we arrive at a problem. The original problem that motivated the use of choice functions for indefinites was that they apparently escape scope islands. Now, it turns out that whenever they have plain scopal readings above scope islands, choice functions are pretty much useless. If one could show that functional readings involve scope island escaping, we would arguably need choice functions to model them. However, it is not trivial to show this. In fact we will show in the next section that for functional readings indefinites don't need to escape scope islands, not because they are choice functions, but for the very simple reason (noted in Schwarzschild, 2002) that functional readings neutralize scope. But then, there doesn't seem to be much motivation left for choice functions. One alternative would be to use Skolem functions instead; cf. Bende-Farkas and Kamp (2001) and Endriss (2009) for such proposals. We will not discuss this option at any length here because they are technically very similar to what we propose in the next section, however, we think that our formalism has the conceptual advantage of being essentially a domain narrowing approach.

\subsection{Functional Readings as Domain Narrowing}

In this section we first propose that functional readings can be thought of as a domain narrowing mechanism, whereby we also present a formalism that models this insight. Second we provide some arguments why our formalism is conceptually superior to Kratzer's (1998) analysis. 
Schwarzschild (2002) discusses cases like (17), which involve scope islands. (17) has two readings that are interesting for this discussion: the wide scope reading in (17a) (most plausible for normal people) and the narrow scope reading in (17b) (plausible for people coming from very rich families). Schwarzschild (2002) claims that the wide scope reading is only apparent.

(17) If some relative of mine dies, I will inherit a fortune.

a. There is a relative of mine such that if he dies I inherit a fortune.

b. If there is a relative of mine who dies, I inherit a fortune.

Assuming that the domain of quantification is restricted to the one and only rich relative of the speaker the narrow scope reading has the same truth conditions as a wide scope reading, since in both cases (with an appropriate semantics for the conditional) only the particularly rich relative can verify or falsify the sentence. This is a general mechanism of scope neutralization. If the hearer assumes that the speaker quantifies over a set containing only one individual, he will never be able to distinguish between narrow and wide scope readings.

While this may seem intuitive, the question could arise why an indefinite is used in (17) in the first place, since a definite expression would be the natural choice whenever the domain of quantification is a singleton set. However, if the speaker were to use the definite article he would imply that either he only has one relative or that the hearer knows which relative he has in mind. What happens here instead is reducing the restrictor to a singleton whose extension is not assumed to be known by the hearer. Rather, the hearer will guess (if supported by the context) that the speaker is actually speaking about one particular relative of his, whom the hearer may not be familiar with.

Schwarzschild claims that domain narrowing to a singleton may also account for apparent intermediate scope readings. Consider King's (1988) famous example given in (18), which exhibits a wide scope reading (18a), an intermediate reading (18b) and a narrow scope reading (18c). Consider also (19). In (19), the indefinite quantifies over a set that is restricted by the value of a variable bound by the quantifier each author. Now, under the assumption that each author has written exactly one book that was deemed pornographic, we get the truth conditional equivalence between the narrow scope and the intermediate scope reading, which is exactly what we wanted. This way the difference between narrow scope and intermediate scope is neutralized in the process of interpretation. To extend this analysis to example (18) all that needs to be done is to postulate a covert domain restriction in (18) that is part of the restrictor NP of the indefinite determiner and that includes a variable bound by the subject quantifier. Adding the covert material he had written is one way to restrict the domain, one may also use different material like he had written 
in one year, he has heard that his best friend has written, he has been working on, he has been reading about, etc.

(18) Each author in this room despises every publisher who would not publish a book that was deemed pornographic.

a. There is a book that was deemed pornographic such that for every author in this room it is the case that he despises every publisher who would not publish that book.

b. For each author in this room there is a book that was deemed pornographic such that he despises every publisher who would not publish that book.

c. For each author in this room it is the case that he despises every publisher such that there is a book that was deemed pornographic that he would not publish.

(19) Each author ${ }_{i}$ in this room despises every publisher who would not publish a book he ${ }_{i}$ had written that was deemed pornographic.

Schwarzschild (2002) requires domain narrowing to a singleton, but whenever there is a domain reduction to a singleton depending on some variable that is quantified over in the sentence, in fact a function is introduced into the restrictor of the existential quantifier: he had written that was deemed pornographic is nothing but a function from individuals $i$ to corresponding books. For this reason we can use the notation in (20). The variable $f$ is a contextually salient function, just as in Kratzer's representation, but it is ontologically simpler than a Skolemized choice function, being of type $\langle e, e\rangle$. This allows us to model the example $(21(=(4))$ as shown in (22).

(20) $[[$ a certain date] $]=\lambda \mathrm{Q}$. true iff $(\exists x)(\mathrm{D}(x) \& f(y)=x \& \mathrm{Q}(x))$

(21) Each husband had forgotten a certain date

(22) $(\forall x)(\mathrm{H}(x) \rightarrow(\exists y)(\mathrm{D}(y) \& f(x)=y \& \mathrm{~F}(y)(x)))$

We propose the notation in (20) as a general framework for functional readings and argue that it is conceptually superior to Kratzer's (1998).

For one thing, (20) transparently models the idea that functional readings are a matter of domain narrowing. Domain narrowing is a pragmatic operation at its core. This means that in order to model functional readings for indefinites that do not code these readings lexically, it suffices to introduce a functional dependency at the level of pragmatics. This is already an advantage over Kratzer (1998), who would be forced to assume lexical ambiguity in any indefinite that allows both functional readings and plain scopal readings. We, on the other hand, may simply assume that whenever an indefinite that does not necessarily trigger functional readings receives a functional interpretation this is a pragmatic process that comes on top of the interpretation as a plain existential quantifier. Of course, for indefinites that lexically encode functional readings, like a certain, we can assume that the requirement for domain narrowing via some functional dependency is lexically coded. 
Second, domain narrowing neutralizes scope ((23a) and (23b) are equivalent). This means that exceptional wide scope readings will never be a problem for functional readings, as in fact there is no need to assume that the indefinite actually gets wide or intermediate scope. We can just as well leave it down in the island and neutralize its scope by inserting a functional dependency. If this is correct, it follows that there is no conceptual reason for introducing choice functions to analyze functional readings. Moreover, since we know that choice functions also fail on plain scopal readings, we can conclude that they are simply obsolete.

(23) a. $(\forall x)(\mathrm{P}(x) \rightarrow(\forall r)(\mathrm{T}(r) \rightarrow(\exists y)(\mathrm{Q}(y) \& f(x)=\mathrm{y} \& \mathrm{R}(x, y, r))))$

b. $(\forall x)(\mathrm{P}(x) \rightarrow(\exists y)(\mathrm{Q}(y) \& f(x)=y \&(\forall r)(\mathrm{T}(r) \rightarrow \mathrm{R}(x, y, r))))$

There are also some practical reasons to believe that a choice function will not do the job anyway. Consider (24) (=(4a)) more carefully. The question is how his wife's birthday can specify the function variable introduced in the first part of the sentence.

(24) Each husband had forgotten a certain date - his wife's birthday.

In our system what needs to be contextually specified is a function from individuals to individuals. It turns out that the most natural conceivable analysis of his wife's birthday is $\lambda$ z.ly. $\mathrm{WB}(\mathrm{z})(\mathrm{y})$, which is precisely a function from individuals to individuals as predicted. This is clearly noted in (23a).

Now consider Kratzer's version. For Kratzer (1998), what needs to be contextually specified is a function from individuals to choice functions. But it is certainly harder to imagine how his wife's birthday can be analyzed in such a way. We have a type mismatch. There is a conceivable rescue for Kratzer's system, but this leads to complications: note that the individual argument of $f$ is he and the set argument must be the set of dates, as shown in (8). First, we would need to split up his wife's birthday to the P of birth of x's wife, which is the structure required by Kratzer's analysis. This could be then equated to $f$. This would be a function, however, that hardly applies to anything but dates, years, decades etc. In fact it is easy to construct examples which will not work for any other set but the restrictor of the indefinite itself, e.g. the $P$ he married, which would be one of those $f$-functions which don't seem to make much sense. Of course, Kratzer (1998) explicitly assumes that $f$ is a partial function, but once it gets so partial that it can only take one set as an argument, its usefulness can be seriously questioned. In addition, equating $f$ and the $P$ of birth of $x$ 's wife would require abstraction over the $P$ variable (which is the property of being a day), which, again, is even technically a nontrivial operation, especially in a semantic framework like Heim and Kratzer (1998). 
The presuppositionality of choice functions turns out to be tricky as well. Choice functions can model existential presuppositions in a very elegant way, since they are undefined whenever the set they take as an argument is empty. Kratzer's (1998) framework predicts that whenever there are no dates at all (4) should be as odd as a presupposition failure can be. In fact, there is no way in Kratzer's system in which the value of $f(x)(\mathrm{D})$ would not be a date. But it seems that the presupposition is not only that there are dates but also that whatever $f$ ultimately selects is a date. In our system this presupposition is easy to incorporate, even though we will mostly omit this part of the formula for readability.

(25) $[$ a certain date $]]=$

asserts : $\lambda \mathrm{Q}$. true iff $(\exists x)(\mathrm{D}(x) \& f(y)=x \& \mathrm{Q}(x))$

and presupposes: $(\forall x) x \in \mathrm{D}_{\mathrm{e}} \rightarrow \mathrm{B}(f(x))$

Now, there is a very interesting difference in predictions between our system and Kratzer's: since we presuppose that $f$ is a function that assigns dates to whatever, we expect any overt specification of $f$ to satisfy this presupposition. Hence, we expect that one can only specify the function variable in an apposition, or with the specificational particle namely, in a construction that overtly specifies a function that will always have dates as a value. This is typically done by saying: the date that such and such. Crucially, however, Kratzer's presupposition works through definedness conditions on choice functions, therefore in principle she would allow any kind of continuation of the type the P of birth of x's wife, for this would identify the function variable sufficiently. But quite generally this is not possible. Hence, for (26) we correctly predict that only the a. continuation is correct, whereas Kratzer would allow the b. continuation as well. We judge (26b) to only be acceptable with the wide reading for a certain doctor, i.e. every woman loves the same doctor, and he saved someone's life.

(26) Every woman loves a certain doctor.

a. - the doctor who saved her life.

b. \# - the man who saved her life.

Summing up: we propose the representation in (20) for functional indefinites and the abandoning of choice functional approaches. We do not claim that Skolemized choice functions will necessarily fail on functional readings but since they lead to problems and additional complexity, we think that an easier, domain narrowing approach should be adopted: we call this referential anchoring.

\section{Referential Anchoring}

In this section we develop the idea of referential anchoring in more detail as a specific kind of domain narrowing and discuss some predictions. 
We call the mechanism which introduces a functional dependency into the restrictor of an indefinite, modelled as an existential quantifier, referential anchoring. The operation can be formally given as the enrichment operator in (28).

(27) $[[\mathrm{a}]]=\lambda \mathrm{P} \lambda \mathrm{Q}$. true iff $(\exists x)(\mathrm{P}(x) \& \mathrm{Q}(x))$

(28) $[[\mathrm{OP}]]=\lambda \Phi \lambda \mathrm{P} \lambda \mathrm{Q} . \Phi(\lambda x . \mathrm{P}(x) \& f(y)=x)(\mathrm{Q})$

(29) $[[\mathrm{OP}(\mathrm{a})]]=\lambda \mathrm{P} \lambda \mathrm{Q}$. true iff $(\exists x)(\mathrm{P}(x) \& f(y)=x \& \mathrm{Q}(x))$

This is a pragmatic operation in the sense that in the case of plain indefinites headed by an indefinite article that may have but do not semantically encode functional readings, this operation comes on top of the semantic representation of the indefinite determiner. We model it as a local operation, but in principle it could be modelled in more procedural terms as well.

Hans Kamp (p.c.) pointed out to us that this operator is not formally restricted to indefinites. But we don't think that this is a problem. There are pragmatic reasons the operator does not apply to other quantifiers. For one thing, domain reduction to one single element would be pragmatically weird in the case of e.g. a universal quantifier: if the speaker knows that the restrictor of every has exactly one element, he has little reason to use the universal quantifier. One benefit is, then, that the choice of different types of expressions denoting existential quantifiers could similarly ease or block the enrichment operation - for instance, there is little reason to allow at least one boy to be narrowed down to a singleton. One can easily put up a blocking argument to this extent.

In the case of indefinite determiners that only allow functional readings we take the existence of the corresponding function and its argument variable to be presupposed, as in (30). We call the function anchoring function and we call the variable the anchor, or anchor variable. Note that we generally assume that indefinite determiners encode additional restrictions on the possible values of $f$ and $y$. We leave this problem for the discussion of the Russian data in Section 4 .

(30) $[[$ a certain $]]=\lambda P \lambda Q$.

asserts : true iff $(\exists x)(\mathrm{P}(x) \& f(y)=x \& \mathrm{Q}(x))$

presupposes : $(\exists f)(\forall x) \mathrm{x} \in \mathrm{D}_{\mathrm{e}} \rightarrow \mathrm{P}(\mathrm{f}(\mathrm{x}))$

Referential anchoring can be conceptualized as a device to account for Fodor and Sag's (1982) original intuition that indefinites may occasionally function as constants, i.e. by using an indefinite the speaker may intend to refer to a particular individual. The constant, hence, stands for the individual which the speaker has in mind at a particular point in the discourse. Referential anchoring captures this idea by making the functional definition of the constant term explicit: we take the function $\lambda z .1 y$. $z$ intends to refer to $y$ at $t$, 
which we then apply to the speaker. $t$ is a time variable that can be used to deal with the situation where the speaker uses several indefinites in a discourse. Whenever the function $\lambda z .1 y$. $z$ intends to refer to $y$ at $t$ is included into the representation of an indefinite, we allow for a singular ("Russellian") proposition interpretation. We do not elaborate on this issue, cf. Kamp and Bende-Farkas (2010) for a very similar view. We call such a case epistemic specificity.

Referential anchoring goes beyond epistemic specificity. Consider for instance the example given in (31) (adapted from Higginbotham, 1987). While in (31a) the hearer can safely assume that the speaker, George, is speaking about the student he has in mind, Jack, the speaker of (31b), may be in no position to say which student George met, but he may still be speaking about the very student George had in mind when uttering (31a). In (31a) the referent of the indefinite is anchored to the speaker. In one reading of (31b) it is anchored to another discourse individual, George. The anchoring to discourse items distinct from the speaker has been called relative specificity in von Heusinger (2002) as a more general case of specificity.

(31) a. George: "I met a certain student of mine today".

b. Jack: "George said that he met a certain student of his today".

Thus referential anchoring can capture this distinction. Note that the function $\lambda z . l y$. $z$ intends to refer to $y$ at $t$ can be applied in both cases. Of course the time variable can be equated to the time at which George told Jack that he met a certain student of his. In the more general (non-quotational) case, however, a weaker function is better suited : $\lambda z .1 y$. the $y$ that $z$ can identify as a witness to $p$, where $\mathrm{p}$ is the actual assertion about $y$. This predicts that if one utters a sentence involving a certain and he has no particular individual in mind but his evidence for the truth of the assertion goes back to some other individual $i$, he can only use a certain felicitously if it is presupposed that $i$ has a particular witness for his conveyed information. In other words, in the case of relative specificity we assume that there is an epistemically specific use of the indefinite by the anchor individual. This also predicts that only sentient individuals can be used as anchors for relative specificity. Note that von Heusinger (2002) is neutral with regard to this prediction.

Referential anchoring, as we understand it, can also capture cases of anchoring to non-sentient individuals. In principle, any function and any anchor will do when no lexically coded constraints apply. The basic representation is highly underspecified by default. Of course, this doesn't exclude the possibility that some/indefinite determiners actually encode the special cases of epistemic or relative specificity. 
Referential anchoring is related in an obvious way to what Breheny (2003) calls an identifying idea and what Kamp and Bende-Farkas (2010) call anchored representation. An anchored representation means that the speaker is ultimately able to identify the individual he intends to refer to by using an indefinite even if he doesn't know exactly who that individual is. Our approach is more general, though less elaborate in terms of psychological reality and plausibility. The obvious advantage is, that it allows readings in which such an identifiability feature is actually hard to assess, as in the case of functional readings under quantifiers: If $f$ and $y$ are constants in the environment in which the indefinite is interpreted, the additional restriction contributed by functional dependency guarantees a singleton indefinite and we get an apparent widest scope reading in non-transparent or quantificational contexts, but if $y$ is bound by some quantifier in the sentence, functional intermediate readings are also possible, for which identifiability seems a very weak feature.

The fact that our system is essentially pragmatic but allows the inclusion of referential anchoring as part of the lexical semantics of some indefinites constitutes an advantage over Kratzer (1998), who necessarily postulates lexical ambiguity for expressions like some. At first sight this is only a matter of theoretical choice, for one could in principle model pragmatic phenomena in the lexicon, so that the pragmatics is responsible for selecting the right lexical entry. But on a closer look, there may be independent considerations against the lexical ambiguity analysis. As argued in Endriss (2009), in some contexts wide readings do not arise even though pragmatically they would be the only felicitous ones, as in the German sentence in (32), which only allows for a narrow scope interpretation for ein Autor ("an author") with unmarked intonation.

(32) Niemand hat ein Buch, das von einem Autor geschrieben wurde, gelesen. Nobody has a book that from a author written has-been read "Nobody read a book that was written by an author".

Kratzer argues that plain exceptional wide scope readings must be accounted for by Skolemized choice functions, and hence, (32) is an explanandum for her theory, to say the least. Since we take Kratzer's (1998) theory to only apply to functional readings, the argument loses some of its power, but shows at least that our pragmatic approach has potential advantages (and no disadvantage) in such cases.

Referential anchoring can combine with additional contextual domain restrictions. (33), on the most natural reading, is verified by a crying boy in the classroom.

(33) We just entered a classroom full of children. A boy was crying. 
Suppose that the speaker of (33) has some boy in mind who is not in the classroom, say, a boy living in another country, and that boy is indeed crying. In the classroom, however, no boy is crying. In this situation, without further context, the sentence is simply false. Yet, if referential anchoring to the speaker were the only mechanism of domain narrowing that applies to indefinites, we would predict the sentence to be true, since the boy the speaker has in mind is indeed crying. Similarly, if we were to assume that domain narrowing with respect to the previously mentioned group of children is the only domain narrowing mechanism at work here, an epistemically specific reading should not be possible. This is because this reading would need an additional domain narrowing to a singleton set; however, the set of boys already narrowed to the class contains more than one boy. The two domain narrowing mechanisms are in conflict. The problem disappears if we assume that referential anchoring is applied on top of the additional domain narrowing which guarantees that the domain of quantification is the set of children in the classroom. One step reduces the restrictor set to the set of boys in the classroom and the other mechanism reduces this already restricted set to a singleton: the singleton domain narrowing comes from referential anchoring.

If this is correct, the fact that partitives are subject to pragmatic domain narrowing has nothing to do with referential anchoring. Regardless of whether the domain of quantification is narrowed contextually, referential anchoring of indefinites may or may not apply. This point is further supported by the observation that a certain can be used with or without partitive expressions, (34a) vs. (34b). This finding neatly ties in with the observation in Kornfilt and von Heusinger (2009) that in Turkish, partitive indefinites need not be specific, i.e. referentially anchored, contrary to what has been formerly suggested by Enç (1991).

(34) a. We just entered a classroom. A certain boy was crying.

b. We just entered a classroom. A certain boy out of the boys in the classroom was crying.

We will show in the next section that referential anchoring can be seen as a general framework to analyze indefinite determiners. In order to achieve the necessary flexibility, we allow the function and the anchor to be completely unrestricted in principle. Hence any function and any anchor will do. Of course if, say, the function is purely abstract and the anchor is, for instance, a possible world, we seemingly depart from our original intention to stick with Fodor and Sag's (1982) intuition that referential anchoring has something to do with referential intentions.

We take referential intentions not to be a necessary aspect of referential anchoring. Instead they are a pragmatically prominent special case that we 
actually expect to find more often in grammaticalized form in natural language precisely because they are particularly useful. In the most general case, referential anchoring only reflects the intuition that the interpretation of an indefinite depends on something, hence in principle giving the hearer some additional clue in the interpretation - this intuition is related to Farkas' (2002) account of dependent indefinites.

\section{Referential Anchoring and Russian Determiners}

In this section we show how the mechanism of referential anchoring can capture the difference between three indefinite determiners in Russian, thus demonstrating its usefulness for linguistic theory. The difference between the three determiners will be analyzed in terms of lexically encoded constraints on referential anchoring.

Russian has no indefinite article. Indefinite noun phrases can be accompanied by different indefinite pronouns used as determiners specifying different interpretations of the respective NP. Indefinite pronouns are formed of a $w$ hword and an affix such as the prefix koe- or the suffix -to or -nibud', as shown in (35). Note that the translations are only approximations.

(35) a. koe-kakaja studentka

KOE-which student

"a certain student (speaker knows which one)"

b. kakaja-to studentka

which-To student

"a certain student (speaker doesn't know which one)"

c. kakaja-nibud' studentka

which-NIBUD' student

"some student or another"

While koe-kakoj ("KOE-which”) and kakoj-to ("which-TO") have been analyzed as specificity markers while others like kakoj-nibud' (“which-NiBuD”") seem to mark non-specificity (cf. Dahl, 1970, 1999; Haspelmath, 1997; Ioup, 1977). However, we will show that all three of them encode functional dependencies, and even the non-specificity of kakoj-nibud' can be captured as a kind of referential anchoring.

\subsection{Indefinite Pronouns with "koe-" and "-to"}

The most important common property of the indefinites accompanied by -to or koe- is that they generally take widest possible scope over both quantifiers and opaque operators regardless of scope islands. Relatively simple cases are 
shown in (36) and (37) in which the universal quantifier interacts with the indefinite NP. The main difference between the two determiners is that while koe-signals that the speaker knows the referent of the indefinite or, in other words, has some particular referent in mind, -to signals precisely the opposite.

(36) Kazhdyj student voschischchaetsja koe-kakim professorom.

Every student admires KOE-which professor

"Every student admires a certain professor the speaker can identify".

(37) Kazhdyj student voschischchaetsja kakim-to professorom.

Every student admires which-то professor

"Every student admires a certain professor the speaker cannot identify".

Kagan (2007) assumes that this difference in identifiability is based on conventional implicatures (Potts, 2007), but we have argued in Geist and Onea (2007) that -to needn't conventionally code at whatever level of semantic representation that the speaker does not have a particular referent in mind. The inference that the referent is not identifiable by the speaker in (37) can be derived as a conversational implicature. This implicature arises from the fact that the hearer knows that if the speaker had some specific professor in mind he would use the koe-item since the referential anchor for -koe indefinites is invariably the speaker. If -to is used, it conversationally implies that the condition for speaker identifiability is not met. We also reject Kagan's (2007) idea that the inference that when using koe- the speaker has a particular referent in mind is a conventional implicature. Our arguments are given below.

There is an additional component of the meaning of koe-, namely that the speaker doesn't indend to disclose the referent of the indefinite in discourse. Kagan (2007) shows that this component has the status of a conventional implicature. This component distinguishes koe-from items which signal identifiability by the speaker in other languages. E.g. Ionin (2006) argues that indefinite this in English signals that the speaker intends to say more about its referent and Chiriacescu and von Heusinger (2010) argue that in Romanian differentially marked direct objects have a similar property. Koe- does the exact opposite.

This leads to the representations in (38) and (39), in which koe- and -to lexicalize different constraints on referential anchoring. We assume that referential anchoring is lexically coded in koe-with the constraint that the referential anchor argument $y$ is the speaker and the function $f$ must be spelled out as intends to refer to. This is shown in (38). For -to we assume a preliminary representation in (39), in which both $f$ and $y$ are underspecified.

(38) $[[$ koe $]]=\lambda \mathrm{P} \lambda \mathrm{Q}$. true iff $(\exists \mathrm{x})(\mathrm{P}(x) \& l y$. speaker intends to refer to $y$ at $t=x \& \mathrm{Q}(x))$

CI: The speaker doesn't want to disclose the identitity of $x$. 
(39) $[[$ to $]]=\lambda \mathrm{P} \lambda \mathrm{Q}$. true if $(\exists \mathrm{x})(\mathrm{P}(x) \& \boldsymbol{f}(\boldsymbol{y})=\boldsymbol{x} \& \mathrm{Q}(x))$ where $f$ and $y$ are contextually determined

(preliminary entry)

Although the speaker is not an appropriate anchor for -to-indefinites, other discourse items are available to serve as referential anchors. Like in (31b), in (40) the appropriate anchor for the -to indefinite is the subject of the matrix clause, Igor, who reported about a particular student he can identify or has in mind. Example (41) can be analyzed in a similar fashion as (40). However, the anchor need not be a sentient one, it can also be the piece of evidence from which the speaker concluded that someone has cheated, and since the arising functional dependency is trivially true, there is no additional impact on the interpretation.

(40) Igor skazal, chto kakoj-to student schpargalil na ekzamene.

Igor said that which-To student cheated on exam

"Igor said that some student cheated on the exam". (The speaker cannot tell which one but Igor can.)

(41) Kakoj-to student schpargalil na ekzamene.

which-TO student cheated on exam

"Some student cheated on the exam". (The speaker cannot identify the student.)

While for koe-the function and the anchor are specified by the lexical entry, for -to the function and the anchor should be specified in some context. This predicts a difference between -to and koe-indefinites: koe-indefinites must always have functional widest readings, since their referential anchor is the speaker which is outside of other sentential operators, while to-items should be more flexible, since the referential anchor could be in principle bound by a sentence internal quantifier. The prediction is borne out: In (42b), koe-gets a wide functional reading, whereas (43) shows that -to can get either a wide functional reading (43b) or a narrow functional reading (43c), depending on the specification of the anchor variable.

(42) a. Kazhdyj student voschischchaetsja koe-kakim professorom.

Every student admires KOE-which professor

"Every student admires a certain professor".

b. $(\forall x)(\mathrm{S}(x) \rightarrow(\exists y)(\mathrm{P}(y) \&$ iz. speaker intends to refer to $z$ at $t=\mathrm{y} \& \mathrm{~A}(x, y)))$

(43) a. Kazhdyj student voschischchaetsja kakim-to professorom.

Every student admires which-то professor

"Every student admires a certain professor".

b. $(\forall x)(\mathrm{S}(x) \rightarrow(\exists y)(\mathrm{P}(y) \& \boldsymbol{f}(\boldsymbol{c})=\boldsymbol{y} \& \mathrm{~A}(x, y)))$

where $\mathrm{c}$ is a contextually bound variable

c. $(\forall x)(\mathrm{S}(x) \rightarrow(\exists y)(\mathrm{P}(y) \& \boldsymbol{f}(\boldsymbol{x})=\boldsymbol{y} \& \mathrm{~A}(x, y)))$

Crucially, however, -to cannot get a "narrow scope" reading under an opaque operator such as hotet" "to want". In (38), Igor needs to know who he wants to 
marry. Hence, assuming that to want quantifies over worlds or situations, we assume that for -to indefinites either the anchor cannot be of type $w$ (orld) or $s$ (ituation), or - as we will see in the next section - there is an independent constraint ruling out this reading.

(44) Igor' hochet zhenit'sja na kakoj-to studentke.

Igor wants marry at which-TO student

"Igor wants to marry a certain student".

In the representation of koe, we did not assume that the information that the speaker has a referent in mind is a conventional implicature. The main reason for this is that conventional implicatures don't seem to be the right kind of semantic device to bind variables which then remain unbound in the asserted representation. Of course, this is not an empirical argument. If indeed koeconventionally implied that the speaker can identify the referent, and we cannot model this inference as a conventional implicature, this would simply mean that we are wrong with our basic representation of koe- as coding constraints on referential anchoring. However, it is not clear how to see the difference, as the typical properties of conventional implicatures follow from our representation as well, without having to assume an additional level of representation. The inference at stake cannot be cancelled, for it is a conventional part of the meaning of koe-, as shown in (45).

(45) Masha govorila $s$ koe-kakim professorom. \# No ja ego ne znaju. Mary spoke with KOE-which professor. But I don't know him. "Mary spoke with a certain professor. But I don't know him".

The inference is detachable, since it comes from a specific morpheme, namely koe-. If we use -to instead of koe- the inference goes away, but, that only shows that there is a semantic difference between koe-and -to, and not that a conventional implicature is involved. The inference is "speaker-oriented" even when the NP with koe-is embedded. Again, this is predicted simply because the anchor variable is invariably bound by the speaker. Occasionally it is possible that the speaker variable gets bound by some attitude holder in the sentence, cf. Malamud (2010), but this is both possible on our analysis and on the conventional implicatures analysis. The fact that koe-indefinites scope over negation also comes for free: From the speaker perspective koe- indefinites are definite descriptions; hence, they cannot be negated. This follows from our formal representation as well, as one can easily reconstruct. Finally, the independence of the at-issue meaning (cf. Potts, 2007), which is the nonpresuppositional conventionally conveyed meaning, is quite impossible to test, since the at-issue meaning of indefinites is the introduction of a new discourse item/referent. Crucially, however, once the discourse item the 
speaker has in mind is present in the discourse one cannot use an indefinite to refer to it, as this would introduce an additional discourse referent. But at least we can show that the meaning component that the speaker can identify the referent of a koe-indefinite can be contrasted, as shown in (46), which certainly doesn't seem to be compatible with the idea that the inference cannot be at-issue.

(46) a. Kto-to ukral knigu iz biblioteki. who-To has stolen a book from the library

"Somebody has stolen a book from the library".

b. Interesno, a koe-kto tozhe! actually, but KOE-who too.

"Actually, somebody too".

Intended meaning: A has also stolen a book from the library, but the speaker doesn't want to tell who it was

Finally there is another apparent problem of our analysis of koe-. In example (47) the koe-indefinite can have a narrow scope reading, according to which different people may have learned different things.

(47) Kazhdyj koe-chemu nauchilsja.

Everybody koe-what learned.

"Everybody learned something". (some things)

Since in our analysis koe-indefinites are anchored to the speaker they are predicted to always take wide scope. The narrow scope reading we find in (47) should be excluded. However, this reading is in fact available. We assume, following the traditional literature on indefiniteness in Russian that koe- is ambiguous (Birkenmaier, 1979; Paducheva, 1985). While one koe- (koe $\left.{ }_{1}-\right)$ indicates that the speaker has a particular single referent in mind - the property we captured in our analysis -, the other koe- $\left(\mathrm{koe}_{2}-\right)$ as in (47) refers to a plurality and means just "more than one" or "many", cf. the two readings of (48).

(48) Koe-kto ushel iz derevni.

коE-who left-sG the village

a. A person (only one person the speaker has in mind) left the village. (koe $\left.{ }_{1}^{-}\right)$

b. Some people (more than one person) left the village. (koe $\left.{ }_{2}^{-}\right)$

Interestingly, the plurality interpretation in (48b) is only available for indefinite pronouns with koe-such as koe-kto ("koe-who"), koe-chto ("koe-what"), etc. For the indefinite determiner koe-kakoj such interpretation never arises, i.e. koe-kakoj mal'chik ("koe-which boy") can only have a singular interpretation. The difference follows if $k o e_{1}$ - and $k o e_{2}$ - are homonymous: while $k o e_{1}-$ can be (a part of) an indefinite determiner, $k o e_{2}$ - can only be (a part of) an 
indefinite pronoun. We assume that unlike $k o e_{1}-k o e_{2}$ - does not involve referential anchoring but just indicates a plurality interpretation.

\subsection{Russian Indefinite Pronouns "-to" vs. "-nibud"}

In this section we will introduce the nibud'-determiner and compare it to -to in order to identify additional grammaticalization patterns of referential anchoring.

Indefinites accompanied by a determiner with the suffix -nibud' must always have narrowest possible scope. The wide scope reading is not available.

(49) a. Kazhdyj student objazatel'no voschischchaetsja kakim-nibud' professorom. Every student necessarily admires which-NiBuD' professor "As a rule, every student admires a professor".

b. * 'the same professor for all students' $\rightarrow$ wide scope

c. OK 'different professors' $\rightarrow$ narrow scope

The question arises whether this means that -nibud' is not referentially anchored at all, or whether in fact-nibud' is referentially anchored to the quantifier that c-commands it. If the latter is the case, nibud' is similar to -to, which can also depend on quantifiers. If so, what is the difference between -nibud' and -to apart from the fact that -to can also take wider readings?

Consider examples (50) and (51) from the Russian National Corpus (RNC), which seem to highlight the difference.

(50) Ochevidno kazhdoe chislo oboznachaet kakuju-to bukvu. probably every number indicates which-то letter

[RNC1] "Probably every number stands for a certain letter".

(51) Dlja kazhdogo teatra u babushki byl kakoj-nibud'

For every theater at grandmother was which-NIBUD'

objazatel'nyj fetish: dlja Bol'shogo- broshka dlja malogo- busiki... [RNC2]

obligatory Fetish for Bolshoj a brooch for Malyj a necklace

"For each theatre the grandmother had a very special obligatory piece of jewellery: for Bolshoj theatre a brooch, for Maly theatre a necklace...".

Our intuition for (50) is that the speaker calls the hearer's attention to the existence of some code which systematically assigns numbers to particular letters. However, this code need not be known by the speaker. The existence of a systematic procedure which maps numbers to letters is just presupposed if -to is used in such a context.

By contrast, the continuation of the clause in (51) contains a pair-list enumeration. This is clearly a case of a "narrow scope" reading of the indefinite with respect to the universal quantifier. In the pair-list enumeration pieces of 
jewelry are arbitrarily assigned to theatres. Of course, even in this case, there is a function which assigns jewelry to theatres, as discussed in Section 2.3.3 but this is prima facie just a different way to conceptualize narrow scope. The crucial observation is the intuition of native speakers that such a function must be unsystematic at least as far as the speaker is concerned. This means that not any function will satisfy the meaning of (51): the systematic ones are ruled out. This is a clear sign that -nibud' does place constraints on possible functions, and, hence, signals some kind of referential anchoring. The function cannot be a trivial Skolem function, obtained by Skolemizing a narrow scope existential, since this would not alter the meaning.

Thus the difference between -to and -nibud' can be described as follows: under a functional narrow reading -to indicates the availability of a systematic function, while-nibud', which also triggers a narrow functional reading of the indefinite, indicates that the function is non-systematic. This intuition can be formulated as a hypothesis that can be tested empirically.

(52) Hypothesis:

In contexts with quantifiers

-to indicates a systematic functional dependency, if its anchor is bound by a quantifier; -nibud' indicates that the function is non-systematic.

This predicts the following preferences for uses of -to and -nibud'.

(53) Predictions:

A. In contexts providing a systematic dependency -to indefinites are preferred.

B. In contexts providing no systematic dependency -nibud' is preferred.

In order to test these predictions we conducted a web-experiment consisting of a context-based forced choice task. The participants had to read a story and judge the target sentences with -to and -nibud' as appropriate or inappropriate in the context of the story. They had to select between three possibilities: a) a sentence with -to, b) a sentence with -nibud' or c) neither. We constructed a total of 8 stories: 4 with a systematic dependency and 4 with an unsystematic dependency. Each participant saw one of the 8 stories and two fillers in a socalled between-subject design. This design was needed since the stories were extremely similar, and we wanted to avoid any bias. The fillers were identical in format to the test items. They were the same for all participants, again, to avoid any uncontrolled bias. Two sample stories with target sentences are given in (54) and (55). The story in (54) is designed to provide a systematic functional dependency where we expected most informants to choose the target sentence with -to. The story in (55) provided a non-systematic dependency and -nibud' was expected to be preferred. 
(54) The story provides a systematic function

John's grandmother likes to go to the theatre. She is a very systematic woman, she used to work as an accountant in a factory. She now carefully developed a system which clothes and jewellery to wear for each theatre. For every theatre, she wears the piece of jewellery which best matches the colour of the seats.

a) Johns grandmother wears for every theatre KAKOJ-TO piece of jewellery.

b) Johns grandmother wears for every theatre KAKOJ-NIBUD' piece of jewellery

c) Both a) and b) are inappropriate in this situation.

(55) The story provides a non-systematic function

John's grandmother is a very weird woman. For some totally incomprehensible reason she wears some special clothes and jewellery for each theatre she visits. When she goes to the Bolshoi theatre she wears her red brooch, when she goes to the Pushkin theatre, she wears a huge golden ring and so on. She is very funny but also crazy.

a) Johns grandmother wears for every theatre KАKOJ-TO piece of jewellery.

b) Johns grandmother wears for every theatre KAKOJ-NIBUD' piece of jewellery

c) Both a) and b) are inappropriate in this situation.

86 native Russian speakers participated in the study. The main results are given in Table 1 .

Table 1. Results of the experiment

\begin{tabular}{llll}
\hline indefinite & + systematic & - systematic & Total \\
\hline -to & $48 \%(22)$ & $26 \%(11)$ & 33 \\
-nibud' & $31 \%(14)$ & $53 \%(22)$ & 36 \\
neither & $20 \%(9)$ & $19 \%(8)$ & 17 \\
Total & $100 \%(45)$ & $100 \%(41)$ & 86 \\
\hline
\end{tabular}

The results are consistent with our predictions in (53). As Table 1 show, in contexts providing a systematic dependency, -to is used in $48 \%$ of all cases. In contexts providing unsystematic dependency -nibud' is preferred (53\%). From a different perspective, -to was selected twice as often in +systematic contexts as in non-systematic ones. We performed a $\chi^{2}$-test on the matrix arising by combining -to, and -nibud with the feature + or - systematic. The choice not to include the neither row is justified by the nature of the $\chi^{2}$ independence test, since in this row we do not expect nor do we find a difference between systematic and non-systematic contexts. The are highly significant: $\chi^{2}=5,324074, \mathrm{df}=1, \mathrm{p}<0.025$. Note that there is quite a lot of noise in the data, due to possible misinterpretations in one of our stimuli, but to achieve statistical significance it was not necessary to remove that item. 
Thus, our hypothesis is confirmed. However, the availability of a systematic, procedurally defined function (Jacobson, 1999) seems to be necessary only for the narrow or intermediate functional readings of Russian -to indefinites, since we have shown above that -to indefinites can have wide functional readings as well. In the latter case we assume that the anchor is not bound by a quantifier in the sentence but rather by some higher discourse referent. When the anchor is co-referential with some already established, higher discourse referent we call it referentially fixed. However, if the anchor is referentially fixed, the systematicity of the function is irrelevant, since we are only interested in the value of the function for one particular argument. For this reason we assume that the function is trivially systematic in such a case. The two interpretational possibilities for -to indefinites can be captured in the final lexical entry given in (56).

(56) $[[$ to $]]=\lambda \mathrm{P} \lambda \mathrm{Q}$. true iff $(\exists \mathrm{x})(\mathrm{P}(x) \& \boldsymbol{f}(y)=\boldsymbol{x} \& \mathrm{Q}(x))$

it is presupposed that $f$ is a systematic contextually determined function

Note that the entry in (56) also immediately predicts that -to will not enter functional dependencies with world or situation variables quantified over by opaque operators, as shown in (44). This is not because worlds were of the wrong type for being anchors for -to, but because functions from worlds to individuals are rather non-systematic.

Some additional words must be said about the determiner -nibud'. This determiner has a very restricted distribution. In simple declarative sentences like (57) -nibud' is excluded. The insertion of a modal operator as in (58) improves the sentence.

(57) *Petja pogovoril s kakim-nibud' juristom.

Petja spoke with which-NiBuD' lawyer

"Petja spoke with some lawyer".

(58) Petja hochet pogovorit' s kakim-nibud' juristom.

Petja wants to-speak with which-NIBUD' lawyer

"Petja wants to speak with some lawyer".

Pereltsvaig (2008) and Yanovich (2005) claim that, besides modals, quantificational DPs such as every boy or every year can license -nibud' as well, cf. (59) and (60).

(59) Kazhdyj mal'chik nes kakuju-nibud' tjazhest'

Every boy carried which-NIBUD' load

"Every boy carried some load".

(60) Kazhdyj god proishodjat kakuju-nibud' izmenenija.

Every year happen which-NIBUD' changes.

"Every year some changes take place". 
Pereltsvaig (2008) does not provide an explicit formal analysis of -nibud' indefinites but refers to Farkas's (1997) analysis of the reduplicated indefinite article egy-egy in Hungarian, which in her opinion may be applied to Russian. There is an obvious issue with this analogy, namely that Hungarian egy-egy is restricted to contexts of quantification over individuals, while -nibud seems unrestricted with regard to the possible anchor variables: individuals as in (59), times as in (60) and possible worlds as in the modal context (58) can serve as appropriate anchors for it. Pereltsvaig observes this and argues that nibud is less restricted than egy-egy. However, in fact this is not entirely correct. We assume that nibud is strongly restricted and can only take situation anchor arguments in the sense of Kratzer (1989).

The introduction of situations is primarily motivated by the following observation. Our informants do not accept -nibud' in all contexts with quantificational DPs such as every boy. Most informants do not accept (61), in which a quantificational DP c-commands the nibud'-indefinite. This suggests that the anchoring of -nibud'-indefinites to individual variables is subject to additional restrictions. These restrictions are not related to the type of quantifier DP. We assume, however, that they can be formulated in situation semantics, since adding any kind of modality in the larger context dramatically improves the examples.

(61) *Kazhdyj mal'chik vchera poceloval kakuju-nibud' odnoklassnicu. Every boy yesterday kissed which-NIBUD' classmate "Yesterday, every boy kissed some classmate".

To capture the occurrences of -nibud' in the above mentioned contexts we extend Yanovich's (2005) analysis of -nibud' as dependent on the variable which must be bound by a universal quantifier. In our notation this idea can be implemented as in (62).

(62) $[[$ nibud'] $]=\lambda \mathrm{P} \lambda \mathrm{Q}$. true if $(\exists \mathrm{x})(\mathrm{P}(x) \& \boldsymbol{f}(\boldsymbol{s})=\boldsymbol{x} \& \mathrm{Q}(x))$

it is presupposed that $\neg s \leq_{\mathrm{p}} w_{0}$

Note that the presupposition that the situation $s$ is not part of the real world $w_{0}$ in (62) is a strong simplification, and additional constraints on situations should be added since not all situations are appropriate anchors for -nibud'. The lexical entry in (62) can account for the very restricted distribution of -nibud' and for the preference to use it in situations which do not provide a systematic function, since functions from (somewhat modal) situations to individuals do not seem to be systematic.

In the reminder of this section we want to compare our analysis with alternative analyses of -to and koe-in other frameworks.

Kagan (2007) captures the difference between koe- and -to without our proposed mechanism of lexically coded referential anchoring. She claims that 
koe- signals inherent speaker identifiability, i.e. it picks up the same individual in every possible world that is compatible with the speaker's worldview. In contrast, -to inherently specifies the speaker non-identifiability of the referent. In her analysis the non-identifiability of the referent by the speaker is the only property in which -to differs from koe-. However, as the discussion of the data above has shown, this view is too simplistic. As we have seen, -to differs from koe- in the felicity of intermediate and narrow functional readings, which are not available for koe-indefinites. The assumption of (non)-identifiability as the only distinctive feature between -to and koe-cannot capture this difference. Moreover, non-specificity markers like -nibud' have also been generally assumed to mark non-identifiability of the referent by the speaker. This suggests that the feature of non-identifiability is not sufficient to capture the differences between indefinite determiners in general.

Yanovich (2005) has proposed that for -to a choice functional analysis in the spirit of Kratzer (1998) is appropriate. According to him -to codes a choice function with no Skolem argument.

(63) $[[$ to $]]=\lambda \mathrm{P} f(\mathrm{P})$, where the speaker knows $f$

(Yanovich, 2005)

However, as we have seen, functional readings are available for -to indefinites, in which the referents of the indefinite functionally depend on discourse items introduced by a quantificational expression. This dependency cannot be captured by a plain choice function without a Skolem argument. Hence, in order to save Yanovich's (2005) analysis one has to introduce a Skolem argument, an anchor in our terminology, with respect to which the choice function denoted by -to is relativized. For this reason we think that our analysis is a significant improvement over Yanovich (2005).

To sum up, we have shown that the distributional properties of -to, -koe and -nibud' can be captured by the assumption that these items lexicalize constraints on referential anchoring. In particular, koe- is the most specified item. It requires the anchor to be the speaker and the function to be interpreted as to intend to refer to $y$ at $t$; -to lexicalizes the constraint that the referential anchoring function must be systematic or the anchor must be fixed; while -nibud' lexicalizes the constraint that the anchor must be a situation that has some modal flavour, the specification of which we leave for further research.

This leads to the question whether referential anchoring could be used as a general framework for modelling the semantic contribution of indefinite determiners cross-linguistically. We conjecture that this is ultimately possible, but there may be exceptions. Bernhard Schwarz (p.c.) has pointed out to us that algun may be such an exception, since it apparently comes with an antisingleton constraint, as in the analysis of Alonso-Ovalle and Menéndez-Benito (2009). Note, however, that even on their analysis, the anti-singleton 
constraint is a constraint on domain narrowing. Now, there are two possibilities to deal with such a case. One would be to attempt to give a competing analysis for algun in terms of referential anchoring. This doesn't seem impossible, as there seems to be a modal component in the interpretation of algún, and this would in principle be suitable as a world/situation-anchor, hence allowing for the modal interpretation more directly than Alonso-Ovalle and Menéndez-Benito (2009) suggest. Of course, one would then need a theory that derives the interpretation in the non-modal cases. We do not claim that such a theory can actually be developed, however, we also do not see why this would be impossible as such. Alternatively one could simply accept AlonsoOvalle and Menéndez-Benito's (2009) analysis and contend that domain narrowing is the most general framework for modelling indefinite interpretation, and referential anchoring is one prominent type of domain narrowing that gets lexicalized in some languages but, crucially, in other languages other possible constraints on domain narrowing can be lexicalized.

\section{Summary and Conclusion}

This paper provides a unified representation of indefinite NPs based on the assumption that the semantic core of indefiniteness involves existential quantification. We assume a general domain narrowing operation called referential anchoring that applies to these existential quantifiers. This operation introduces a functional dependency into the restrictor of the existential quantifier. Moreover, we have shown that it is possible to model a wide array of readings indefinites may have in terms of referential anchoring. In addition, we claim that referential anchoring may be a pragmatic operation but can also get grammaticalized in natural language, therefore becoming part of the semantic representation of indefinite determiners. We have demonstrated how this can be modelled for Russian indefinite determiners.

We have also argued that referential anchoring as such is not responsible for exceptional scope readings discussed in the literature, even though many linguists have used similar formal tools to derive those readings. This discussion is less important for us, since our primariy aim was to capture the meaning variation of indefinite determiners, which indeed appear to lexicalize constraints on referential anchoring. Since the exceptional scope discussion is - as far as we can judge it - not decided yet, our approach hinges on the right theory of scope for indefinites. However, we assume that it is conceptually compatible with a great number of possible approaches. The next step would be to check whether the application of referential anchoring can adequately 
capture differences between indefinite determiners in other languages - this work we leave for the future.

\section{Sources}

[RNC]: Russian National Corpus

[RNC 1]: Tim Sobakin. Shifry. 1990

[RNC2]: Inka 2004

\section{References}

Alonso-Ovalle, Luis and Paula Menéndez-Benito. 2009. Modal indefinites. Natural Language Semantics 18: 1-31.

Bende-Farkas, Ágnes and Hans Kamp. 2001. Indefinites and binding: from specificity to incorporation. Lecture notes (revised version) for 13th ESSLLI, Helsinki.

Breheny, Richard. 2003. Exceptional scope and domain restriction. In M. Weisgerber (ed.), Proceedings of SuB7, Konstanz: 38-52.

Birkenmaier, Willy. 1979. Artikelfunktionen in einer artikellosen Sprache. Studien zur nominalen Determination im Russischen. München (Forum Slavicum 34).

Chierchia, Gennaro. 2001. A puzzle about indefinites. In G.C. Cecchetto and M.T. Guasti (eds.), Semantic Interfaces, 51-89. Stanford, CA: CSLI Publications.

Chierchia, Gennaro. 1993. Questions with quantifiers. Natural Language Semantics 1: $181-234$.

Chiriacescu, Sofiana and Klaus von Heusinger. 2010. Discourse prominence and Pe-marking in Romanian. International Review of Pragmatics 2: 298-332.

Dahl, Östen. 1970. Some notes on indefinites. Language 46: 33-41.

Dahl, Östen. 1999. Review of Indefinite Pronouns by Martin Haspelmath. Linguistics and Philosophy 22: 663-678.

Dekker, Paul. 2004. The pragmatic dimension of indefinites. Research on Language and Computation 2: 365-399.

Dekker, Paul. 2008. A multi-dimensional treatment of quantification in extraordinary English. Linguistics and Philosophy 31: 101-127.

Ebert, Christian and Cornelia Endriss. 2007. Functional topics. In Proceedings of the SuB11, Barcelona: 194-208.

Enç, Mürvet. 1991. The semantics of specificity. Linguistic Inquiry 22: 1-25.

Endriss, Cornelia. 2009. Quantificational topics - A scopal treatment of exceptional wide scope phenomena. Studies in Linguistics and Philosophy. Berlin: Springer.

Farkas, Donka. 1995. Specificity and scope. In L. Nash and G. Tsoulas (eds.), Langues et Grammaire 1: 119-137.

Farkas, Donka. 1997. Dependent indefinites. In F. Corblin, D. Godard and J.-M. Marandin (eds.), Empirical Issues in Formal Syntax and Semantics, 243-267. Bern: Peter Lang.

Farkas, Donka. 2002. Specificity distinctions. Journal of Semantics 19: 213-243.

Farkas, Donka and Adrian Brasoveanu. 2009. Scope and the grammar of choice. In Proceedings of the Tenth Symposium on Logic and Language (LoLa10): 119-130. 
Fodor, Janet Dean and Ivan A. Sag. 1982. Speaker's reference and quantificational indefinites. Linguistics and Philosophy 5: 355-398.

Geist, Ljudmila. 2008. Specificity as referential anchoring: evidence from Russian. In A. Grønn (ed.), Proceedings of SuB12, Oslo: 151-164.

Geist, Ljudmila and Edgar Onea. 2007. Specificity and implicatures. In M. Aloni, P. Dekker and

F. Roelofsen (eds.), Proceedings of the Sixteenth Amsterdam Colloquium, December 17-19, Amsterdam: 109-114.

Haspelmath, Martin. 1997. Indefinite Pronouns. Oxford: Clarendon Press.

Heim, Irene. 2011. Definiteness and indefiniteness. To appear in: C. Maienborn, K. von Heusinger and P. Portner (eds.), Semantics: An International Handbook of Natural Language Meaning. Berlin: de Gruyter.

Heim, Irene and Angelika Kratzer. 1998. Semantics in Generative Grammar. Malden, MA: Blackwell.

Higginbotham, James. 1987. Indefinites and predication. In E. Reuland and A. Meulen (eds.), The Representation of (In)definiteness, 43-70. Cambridge, MA: The MIT Press.

Hintikka, Jaakko. 1986. The semantics of 'a certain'. Linguistic Inquiry 17: 331-336.

Ionin, Tania. 2006. THIS is definitely specific: specificity and definiteness in article systems. Natural Language Semantics 14: 175-234.

Ionin, Tania. 2010. An experimental study on the scope of (un)modified indefinites. International Review of Pragmatics 2: 228-265.

Ioup, Georgette. 1977. Specificity and the interpretation of quantifiers. Linguistics and Philosophy 1: 233-245.

Jacobson, Pauline. 1999. Towards a variable-free semantics. Linguistics and Philosophy 22: $117-184$.

Kagan, Olga. 2007. Specificity and the speaker's worldview. Talk given at "Funny indefinites", ZAS Berlin. 7 July 2007.

Kamp, Hans and Ágnes Bende-Farkas. 2010. Epistemic specificity from a communication theoretic perspective. Unpublished manuscript, University of Stuttgart.

King, Jeffrey C. 1988. Are indefinite descriptions ambiguous? Philosophical Studies 53: $417-440$.

Kornfilt, Jaklin and Klaus von Heusinger. 2009. Specificity and partitivity. In R. Shibagaki and R. Vermeulen (eds.), MIT Working Papers in Linguistics (MWPL) 58: 19-40.

Kratzer, Angelika. 1998. Scope or pseudo-scope? Are there wide-scope indefinites? In S. Rothstein (ed.), Events in Grammar, 163-196. Dordrecht: Kluwer.

Kratzer, Angelika. 2003. A note on choice functions in context. Unpublished manuscript, University of Massachusetts, Amherst.

Kratzer, Angelika. 1989. An investigation of the lumps of thought. Linguistics and Philosophy 12: 607-653.

Malamud, Sophia Alexandra. 2010. Specificity as referential anchoring in Russian: shifting speakers and Hamblin sets. Talk given at "Specificity from Theoretical and Empirical Points of View”, Stuttgart. 2 September 2010.

Matthewson, Lisa. 1999. On the interpretation of wide-scope indefinites. Natural Language Semantics 7: 79-134.

Paducheva, Elena V. 1985. Vyskazyvanie i ego sootnesennost' s dejstvitel'nost'ju. Moscow: Nauka.

Pereltsvaig, Asya. 2008. Russian nibud'-series as markers of co-variation. In N. Abner and J. Bishop (eds.), Proceedings of the 27th West Coast Conference on Formal Linguistics: 370-378.

Potts, Christopher. 2007. Conventional implicatures, a distinguished class of meanings. In G. Reiss and G. Ramchand (eds.), The Oxford Handbook of Linguistic Interfaces, 475-501. Oxford: Oxford University Press. 
Reinhart, Tania. 1997. Quantifier scope: how labour is divided between QR and choice functions. Linguistics and Philosophy 20: 335-397.

Schwarz, Bernhard. 2001. Two kinds of long distance indefinites. In R. van Rooy and M. Stokhof (eds.), Proceedings of the Thirteenth Amsterdam Colloquium. Amsterdam: ILLC: 192-197.

Schwarzschild, Roger. 2002. Singleton indefinites. Journal of Semantics 19: 289-314.

Sharvit, Yael. 1997. The Syntax and Semantics of Functional Relative Clauses. PhD thesis, Rutgers University.

Steedman, Mark. 2007. Surface-compositional scope-alternation without existential quantifiers. Unpublished manuscript, University of Edinburgh.

von Heusinger, Klaus. 2002. Specificity and definiteness in sentence and discourse structure. Journal of Semantics 19: 245-274.

von Heusinger, Klaus. 2011. Specificity. To appear in: C. Maienborn, K. von Heusinger and P. Portner (eds.), Semantics: An International Handbook of Natural Language Meaning. Berlin: de Gruyter.

Winter, Yoad. 1997. Choice functions and the scopal semantics of indefinites. Linguistics and Philosophy 20: 399-467.

Yanovich, Igor. 2005. Choice-functional series of indefinite pronouns and Hamblin semantics. In E. Georgala and J. Howell (eds.), Proceedings SALT 15: 309-326. 